\title{
Shunt Active Power Filter for Energy Quality Improvement in Distributed Generation Systems
}

\author{
José Aglailson Silva de Olivindo, Isaac Rocha Machado \\ Department of Electrical and Computer Engineering \\ Federal University of Ceara, Sobral, Ceara 62.010-560, Brazil \\ aglailson.olivindo@gmail.com, isaacmachado@gmail.com
}

\begin{abstract}
This paper presents an application of a shunt active power filter (SAPF) for energy quality improvement in a power system composed of nonlinear loads and distributed wind generation. The control of SAPF is implemented without harmonic detection schemes and by linear quadratic regulators with integral action. The performance of the SAPF is evaluated by the current total harmonic distortions and the power factor at the point of common coupling of the power system. The analysis of non-active powers compensation is based on the instantaneous power theory concepts. The control system uses only the power grid currents and voltages measurements, and DC-link voltage of the SAPF. The validation of the control strategy is done through computational simulations implemented in the PSCAD/EMTDC software.
\end{abstract}

Keywords-harmonic compensation; power factor correction; linear quadratic regulator; shunt active power filter; distributed generation.

\section{INTRODUCTION}

The development and search for technology capable of improving the productivity and efficiency of industrial processes, or even of household equipment, have influenced the use of switched electronic converters and static drives, which results in nonlinear loads connected to the power grid [1]. In addition, the distributed generation (DG) increase in low voltage power systems has caused an increase of the harmonic distortions [2].

Although, in many cases, the power distribution system can be considered robust enough to withstand small oscillations and harmonic distortions generated by non-linear loads and DG, the increase of these elements affects the quality of the energy, since it contributes to increase the current and voltage waveforms distortions, reactive power consumption and consequent reduction of the power factor $(\mathrm{PF})$ at the point of common coupling (PCC) [3]. Moreover, nonlinear loads that change randomly contribute to increase of asymmetric harmonic currents capable of causing voltage drops in the electric network [4].

One solution adopted for the harmonic filtering in the power systems is the use of a shunt active power filter (SAPF), a device based on power electronics that improves the energy quality [5][7]. The SAPF is basically used to compensate current harmonics, but can also be used to reduce current unbalances and power factor improvement, compensating the non-active powers required by the system, reducing the problems caused by the equipment's nonlinearities [8], [9].
Some studies were carried out with the purpose of evaluating the harmonic detection and SAPF current controls methodologies using harmonic extractor-based strategies [5], [10], [11]. However, to adapt the energy quality in the PCC to acceptable levels, the controllability of the grid current must be obtained, making it sinusoidal, for harmonic correction, or with the same waveform and phase of the PCC voltage, for a power factor correction [12], [13]. To do it, the SAPF can use balancedenergy-based schemes, based on system active power balanced. This control strategy reduces the SAPF complexity, since there are not necessary the load and filter line current measurements [14], [15].

This paper proposes an application of a SAPF with a control strategy based in a linear quadratic regulator with integral action (LQRI) and the balanced-energy-based schemes to improve the energy quality of a low voltage distribution network with dynamic nonlinear load and distributed wind generation with random wind. The performance of the control scheme is demonstrated with simulation results, studying the waveforms, current harmonic contents of the system and power factor at PCC.

\section{SYSTEM DESCRIPTION AND POWER FLOW}

The electrical system studied in this work is presented in Fig. 1. The power distribution system is represented by its Thevenin equivalent circuit. The SAPF, nonlinear loads and distributed wind generation are connected in the PCC. The SAPF topology is a 6-pulse voltage source inverter (VSI). The nonlinear load is composed by a three-phase 6-pulse thyristor-controlled rectifier with inductive load and single-phase diode rectifier with resistive load. The DG is composed of a wind turbine equipped with a double feed induction generator (DFIG).

To understand the balanced-energy-based scheme in SAPF, are used the concepts of instantaneous power theory.

\section{A. Instantaneous Power Theory}

The instantaneous power theory, or $p q$ theory, defines that any three-phase electrical system can be analyzed in terms of its instantaneous powers, in the time domain [16]. For three-wire three-phase balanced circuits, that is without zero sequence components, the instantaneous powers can be given in terms of its real $(p)$ and imaginary $(q)$ powers, that can be divided into average and oscillating components.

$$
\begin{aligned}
& p=\bar{p}+\tilde{p} \\
& q=\bar{q}+\tilde{q}
\end{aligned}
$$




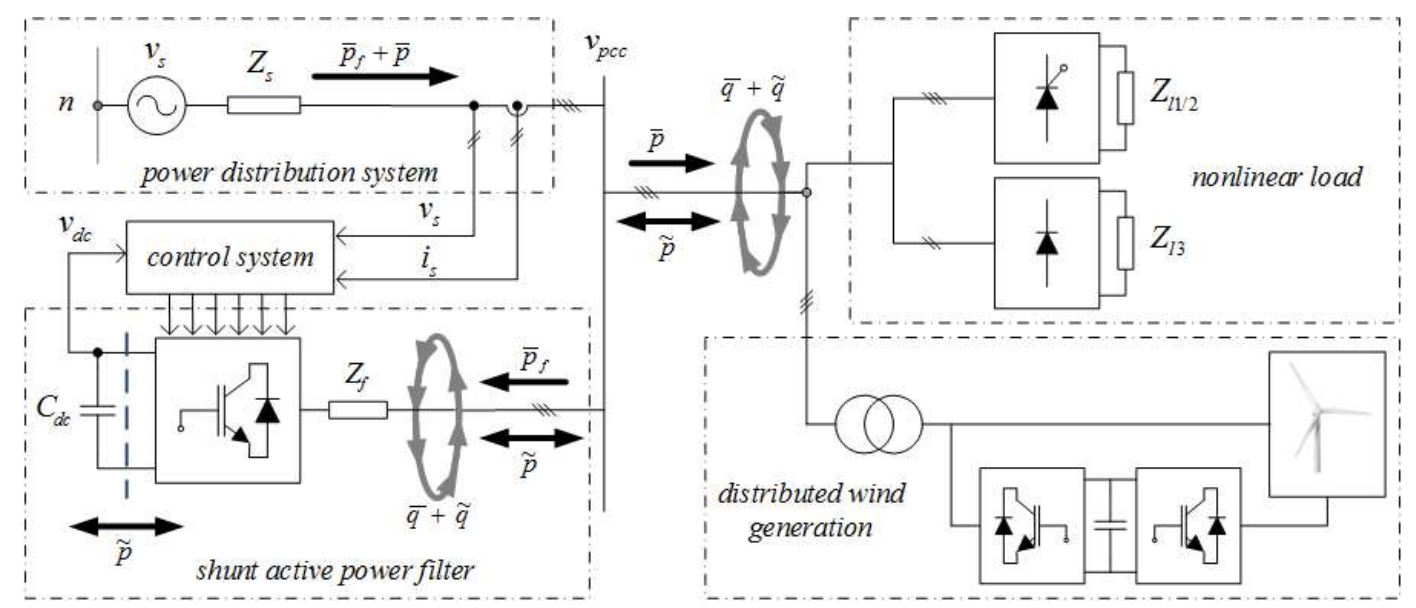

Fig. 1. Diagram of distributed generation system studied and graphical representation of the instantaneous powers.

The average real power component $(\bar{p})$ represents the energy, per unit time, flowing in one direction. The average components $\bar{p}$ and $\bar{q}$ correspond, respectively, to the three-phase active and reactive powers defined by the conventional theory of alternating current circuits.

The oscillating real power component $(\tilde{p})$ represents the energy, per unit of time, that is exchanged between the source and the DG-load whose average value, over time, is zero. More precisely, the oscillating components $\tilde{p}$ and $\tilde{q}$ are related to the harmonics presence in the power system.

Ideally the SAPF should compensate the $q$ and $\tilde{p}$ power components required by the DG-load set. If this is achieved, the electrical grid will see the SAPF-DG-load set as a purely resistive element, supplying only the average real power component, as seen in Fig. 1.

The instantaneous imaginary power $q$ circulates between the phases of the power system. For the compensation of this component it is necessary that the SAPF synthesize an imaginary power of the same magnitude, but with a opposite circulation to that required by the DG-load set, to apply the cancellation.

The SAPF action causes a real power flow by the VSI equal to the sum of the average real power $\bar{p}_{f}$ and the oscillating real power $\tilde{p}$. The real power $\bar{p}_{f}$ is supplied by the power grid to restore the switching and the passive elements losses of the VSI.

\section{SYSTEM MODELING}

Fig. 2 shows the analyzed system equivalent circuit, composed of: electrical grid, represented by your Thevenin equivalent circuit; SAPF, represented by a voltage source in series with the filter impedance; nonlinear loads, represented by an impedance in parallel with a harmonic current source; and DG, represented by a current source.

Applying the Kirchhoff's voltage law on the circuit from $n$ to $m$ point, the following expression is obtained:

$$
v_{s}-r_{s} i_{s}-l_{s} \frac{d i_{s}}{d t}+r_{f} i_{f}+l_{f} \frac{d i_{f}}{d t}-v_{f}=0,
$$

where $v_{m n}=0 \mathrm{~V}$.

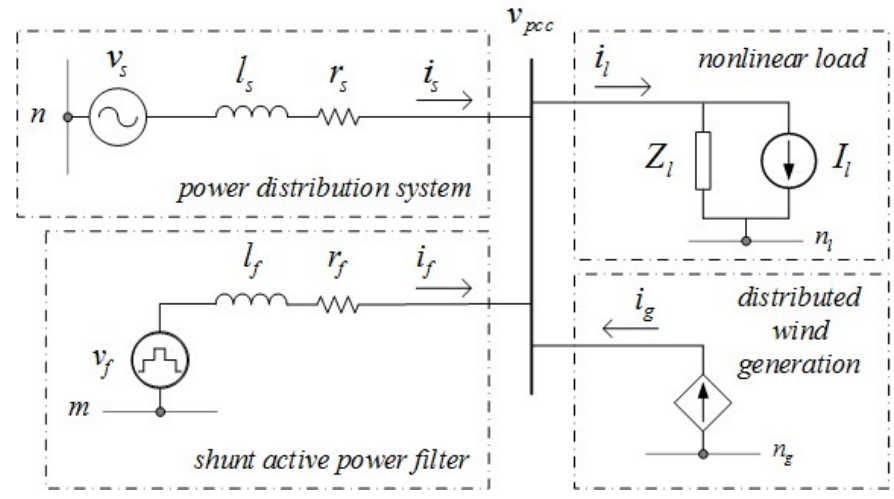

Fig. 2. Equivalent circuit of the proposed system.

The representation of the currents and voltages in terms of the state variables model, in the synchronous frame, is given by [17]:

$$
\begin{gathered}
\frac{d i_{s d}}{d t}=-\frac{r_{u}}{l_{u}} i_{s d}+\omega i_{s q}-\frac{d_{d}}{l_{u}} v_{d c}+\frac{1}{l_{u}} v_{e d} \\
\frac{d i_{s q}}{d t}=-\omega i_{s d}-\frac{r_{u}}{l_{u}} i_{s q}-\frac{d_{q}}{l_{u}} v_{d c}+\frac{1}{l_{u}} v_{e q} \\
\frac{d v_{d c}}{d t}=\frac{3}{2 C}\left(d_{d} i_{s d}+d_{q} i_{s q}\right)
\end{gathered}
$$

where:

$r_{u}$ - equivalent resistance of the series connection between the grid and SAPF resistors, $r_{u}=r_{s}+r_{f}$;

$l_{u}$ - equivalent inductance of the series connection between the grid and SAPF inductors, $l_{u}=l_{s}+l_{f}$;

$d_{k}$ - VSI switching state function;

$v_{e k}$ - voltage disturbances in the plant model.

The $a b c$ to $d q$ coordinates transformation is given by the Park transform, applied without the homopolar component:

$$
\boldsymbol{T}_{\text {park }}=\frac{2}{3}\left[\begin{array}{lll}
\sin (\omega t) & \sin \left(\omega t-\frac{2 \pi}{3}\right) & \sin \left(\omega t+\frac{2 \pi}{3}\right) \\
\cos (\omega t) & \cos \left(\omega t-\frac{2 \pi}{3}\right) & \cos \left(\omega t+\frac{2 \pi}{3}\right)
\end{array}\right]
$$

The Park transformation for voltages, current and switching state function is given by: 


$$
\begin{aligned}
{\left[\begin{array}{ll}
v_{d} & v_{q}
\end{array}\right]^{T} } & =\boldsymbol{T}_{\text {park }}\left[\begin{array}{lll}
v_{a} & v_{b} & v_{c}
\end{array}\right]^{T} \\
{\left[\begin{array}{ll}
i_{s d} & i_{s q}
\end{array}\right]^{T} } & =\boldsymbol{T}_{\text {park }}\left[\begin{array}{lll}
i_{s a} & i_{s b} & i_{s c}
\end{array}\right]^{T} \\
{\left[\begin{array}{ll}
d_{d} & d_{q}
\end{array}\right]^{T} } & =\boldsymbol{T}_{\text {park }}\left[\begin{array}{lll}
d_{a} & d_{b} & d_{c}
\end{array}\right]^{T}
\end{aligned}
$$

By system linearizing around the operating point it is possible to describe it as:

$$
\begin{gathered}
\dot{\boldsymbol{x}}_{-}=\boldsymbol{A} \boldsymbol{x}_{\sim}+\boldsymbol{B} \boldsymbol{u}_{\sim}+\boldsymbol{E} \boldsymbol{v}_{\sim} \\
\boldsymbol{y}_{\sim}=\boldsymbol{C} \boldsymbol{x}_{\sim}
\end{gathered}
$$

where: $\boldsymbol{A}, \boldsymbol{B}, \boldsymbol{E}$ and $\boldsymbol{C}$ are, respectively, the state, the control, the disturbance and the output matrices, given by:

$$
\begin{gathered}
\boldsymbol{A}=\left[\begin{array}{ccc}
-\frac{r_{u}}{l_{u}} & \omega & -\frac{D_{d}}{l_{u}} \\
-\omega & -\frac{r_{u}}{l_{u}} & -\frac{D_{q}}{l_{u}} \\
\frac{3 D_{d}}{2 C} & \frac{3 D_{q}}{2 C} & 0
\end{array}\right], \quad \boldsymbol{B}=\left[\begin{array}{cc}
-\frac{V_{d c}}{l_{u}} & 0 \\
0 & -\frac{V_{d c}}{l_{u}} \\
\frac{3 I_{s d}}{2 C} & \frac{3 I_{s q}}{2 C}
\end{array}\right] \\
\boldsymbol{E}=\left[\begin{array}{cc}
\frac{1}{l_{u}} & 0 \\
0 & \frac{1}{l_{u}} \\
0 & 0
\end{array}\right], \boldsymbol{C}=\left[\begin{array}{ccc}
1 & 0 & 0 \\
0 & 1 & 0 \\
0 & 0 & 1
\end{array}\right]
\end{gathered}
$$

and $\boldsymbol{x}_{\sim}, \boldsymbol{u}_{\sim}, \boldsymbol{v}_{\sim}, \boldsymbol{y}_{\sim}$ are the state, the control, the disturbance and the output vectors as follow:

$$
\boldsymbol{x}_{\sim}=\boldsymbol{y}_{\sim}=\left[\begin{array}{l}
i_{s d_{\sim}} \\
i_{s q_{\sim}} \\
v_{d c_{\sim}}
\end{array}\right], \quad \boldsymbol{u}_{\sim}=\left[\begin{array}{l}
d_{d_{\sim}} \\
d_{q_{\sim}}
\end{array}\right], \quad \boldsymbol{v}_{\sim}=\left[\begin{array}{l}
v_{e d} \\
v_{e q_{\sim}}
\end{array}\right]
$$

\section{CONTROLler Design}

The SAPF control consists of an inner current loop to control the $i_{s d}$ and $i_{s q}$ components, responsible for maintaining null $\tilde{p}$ and $q$ power grid contribution, and an outer voltage loop, responsible for maintaining the SAPF DC bus voltage at its reference value.

Applying the method in [18] to design the linear quadratic regulator, the adjustment of the regulator is performed by the following control law:

$$
\boldsymbol{u}=-\boldsymbol{K} \boldsymbol{x},
$$

where $\boldsymbol{K}$ is the state-feedback gain matrix, whose optimal value results in a $\boldsymbol{u}$ capable of minimize the following cost function,

$$
J=\int_{0}^{\infty}\left(\boldsymbol{x}^{T} \boldsymbol{Q} \boldsymbol{x}+\boldsymbol{u}^{T} \boldsymbol{R} \boldsymbol{u}\right) d t
$$

where $\mathbf{Q}$ and $\mathbf{R}$ are the state and control weighting matrices, symmetric and square.

The addition of the integral action in the LQR regulator applied to these states modifies the control law of the system that becomes:

$$
\boldsymbol{u}=-\boldsymbol{K}_{P} \boldsymbol{x}+\boldsymbol{K}_{\boldsymbol{I}} \boldsymbol{\xi}
$$

where $\boldsymbol{K}_{\boldsymbol{P}}$ and $\boldsymbol{K}_{\boldsymbol{I}}$ are, respectively, the proportional and integral gains matrices and $\xi$ is the vector composed by the output integrator error in each controller given by:

$$
\xi_{\sim}=\left[\int i_{d s_{\sim}} \int i_{q s_{\sim}} \int v_{d c_{\sim}}\right]^{T}
$$

Using the augmented matrix concept, the equivalent system with integrative action is written as,

$$
\left[\begin{array}{l}
\dot{x}_{-} \\
\dot{\xi}_{-}
\end{array}\right]=\left[\begin{array}{cc}
A & 0 \\
-C & 0
\end{array}\right]\left[\begin{array}{l}
x_{\sim} \\
\xi_{\sim}
\end{array}\right]+\left[\begin{array}{l}
B \\
0
\end{array}\right] \boldsymbol{u}_{\sim}+\left[\begin{array}{l}
E \\
0
\end{array}\right] \boldsymbol{v}_{\sim}
$$

For the control with integrative action, the cost function to be minimized, written as $J=J_{x}+J_{u}$, is composed by:

$$
\begin{gathered}
\boldsymbol{J}_{\boldsymbol{x}}=\left[\begin{array}{l}
\boldsymbol{x} \\
\boldsymbol{\xi}
\end{array}\right]^{T}\left[\begin{array}{cccccc}
Q_{i_{s d}} & 0 & 0 & 0 & 0 & 0 \\
0 & Q_{i_{s q}} & 0 & 0 & 0 & 0 \\
0 & 0 & Q_{v d c} & 0 & 0 & 0 \\
0 & 0 & 0 & Q_{\int i_{s d}} & 0 & 0 \\
0 & 0 & 0 & 0 & Q_{\int i_{s q}} & 0 \\
0 & 0 & 0 & 0 & 0 & Q_{\int v d c}
\end{array}\right]\left[\begin{array}{l}
\boldsymbol{x} \\
\boldsymbol{\xi}
\end{array}\right] \\
\boldsymbol{J}_{\boldsymbol{u}}=\boldsymbol{u}^{T} \cdot\left[\begin{array}{ccc}
R_{i_{s d}} & 0 & 0 \\
0 & R_{i_{s q}} & 0 \\
0 & 0 & R_{v_{d c}}
\end{array}\right] \boldsymbol{u}
\end{gathered}
$$

The setting point is obtained making time derivatives of (4)(6) equal to zero and substituting the variables by the follow steady-state values.

$$
i_{s d}=I_{s d}, i_{s q}=0, v_{d c}=V_{d c}, D_{d}=\frac{V \sqrt{2}}{V_{d c}}, D_{q}=0
$$

Solving the Riccati equation,

$$
\boldsymbol{A}^{T} \boldsymbol{P}+\boldsymbol{P} \boldsymbol{A}-\boldsymbol{P} \boldsymbol{B} \boldsymbol{R}^{-1} \boldsymbol{B}^{T} \boldsymbol{P}+\boldsymbol{Q}=\mathbf{0},
$$

where $\boldsymbol{P}$ is the matrix solution, is obtained the matrix gain $\boldsymbol{K}$ given by,

$$
\boldsymbol{K}=\boldsymbol{R}^{-1} \boldsymbol{B}^{T} \boldsymbol{P}
$$

that is divided into two parts $\boldsymbol{K}=\left[\boldsymbol{K}_{\boldsymbol{P}(\mathbf{3} \times \mathbf{3})} \boldsymbol{K}_{I(3 \times 3)}\right]$, Fig. 3 .

The phase angle of the PCC voltage vector, to Park transformation, is determined by using a PLL.

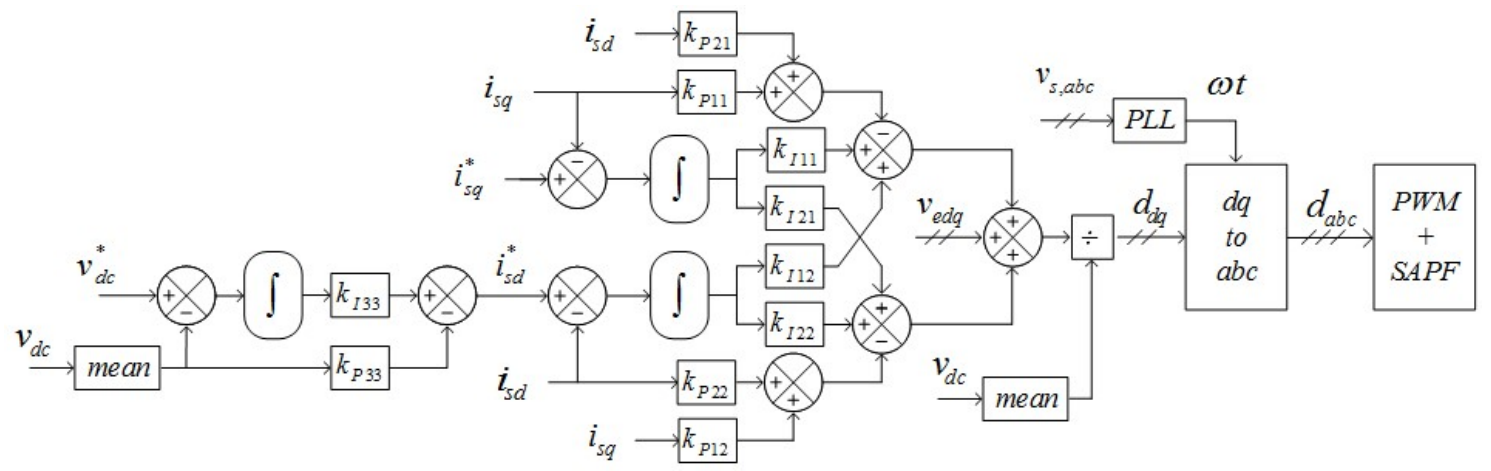

Fig. 3. Block diagram of control system. 


\section{CASE Study}

To evaluate the control strategy performance is used the PSCAD/EMTDC software. The simulated power system parameters are presented in Table I.

TABLE I

Power System Parameters

\begin{tabular}{|c|c|}
\hline \multicolumn{2}{|c|}{ Grid Parameters } \\
\hline line to line voltage (rms) & $380 \mathrm{~V}$ \\
\hline frequency & $60 \mathrm{~Hz}$ \\
\hline impedance & $0.8+s 0.22 \Omega$ \\
\hline \multicolumn{2}{|c|}{ Load Parameters } \\
\hline impedance of three-phase load $\left(Z_{l 1}\right)$ & $15+s 0.02 \Omega$ \\
\hline impedance of three-phase load $\left(Z_{l 2}\right)$ & $7.5+s 0.02 \Omega$ \\
\hline impedance of single-phase load $\left(Z_{l 3}\right)$ & $100 \Omega$ \\
\hline
\end{tabular}

\begin{tabular}{ll}
\hline \multicolumn{1}{c}{ SAPF Parameters } & \\
\hline coupling inductance & $2 \mathrm{mH}$ \\
\hline dc bus voltage & $800 \mathrm{~V}$ \\
\hline dc bus capacitance & $4.7 \mathrm{mF}$ \\
\hline
\end{tabular}

The nonlinear load is composed by a three-phase 6-pulse thyristor-controlled rectifier with inductive load and a singlephase diode rectifier with resistive load. The nonlinear load is connected to the PCC by a $1.5 \mathrm{mH}$ coupling inductance.

The DG is composed of a wind turbine equipped with a DFIG, simulated considering random wind.

Table II shows the simulation stages. Load variations (and consequently $p$ and $q$ profiles changes) are applied to evaluate the SAPF performance. The distributed wind generation connection increases the $p$ profile intermittence, since the wind assumes a random variation.

\section{TABLE II}

\section{Simulation Stages}

\begin{tabular}{|c|c|}
\hline Simulation Time & Equipment and Loads Connected on the PCC \\
\hline step $1(0.0-1.0 \mathrm{~s})$ & $\begin{array}{l}\text { three-phase controlled rectifier with firing angle } \\
\text { of } 45^{\circ} \text { and } Z_{11} \text { load }\end{array}$ \\
\hline step $2(1.0-2.5 \mathrm{~s})$ & $\begin{array}{l}\text { SAPF }+ \text { three-phase controlled rectifier with firing } \\
\text { angle of } 45^{\circ} \text { with } Z_{11} \text { load }\end{array}$ \\
\hline step $3(2.5-5.0 \mathrm{~s})$ & $\begin{array}{l}\mathrm{DG}+\mathrm{SAPF}+\text { three-phase controlled rectifier with } \\
\text { firing angle of } 45^{\circ} \text { with } Z_{11} \text { load }\end{array}$ \\
\hline step $4(5.0-7.5 \mathrm{~s})$ & $\begin{array}{l}\mathrm{DG}+\mathrm{SAPF}+\text { three-phase controlled rectifier with } \\
\text { firing angle of } 45^{\circ} \text { with } Z_{12} \text { load }\end{array}$ \\
\hline step $5(7.5-10$. & same that the step 3 \\
\hline step $6(10.0-12.5 \mathrm{~s})$ & $\begin{array}{l}\mathrm{DG}+\mathrm{SAPF}+\text { three-phase controlled rectifier with } \\
\text { firing angle of } 55^{\circ} \text { with } Z_{11} \text { load }\end{array}$ \\
\hline step $7(12.5-15.0 \mathrm{~s}$ & same that the step 3 \\
\hline step $8(15.0-17.5 \mathrm{~s})$ & $\begin{array}{l}\mathrm{DG}+\mathrm{SAPF}+\text { three-phase controlled rectifier with } \\
\text { firing angle of } 45^{\circ} \text { and } Z_{11} \text { load }+ \text { single-phase } \\
\text { diode rectifier with } Z_{13} \text { load }\end{array}$ \\
\hline step $9(17.5-20.0 \mathrm{~s})$ & same that the step 3 \\
\hline
\end{tabular}

\section{A. SAPF Connection}

In the first step, the power grid is supplying the nonlinear load (thyristor-controlled rectifier with firing angle of $45^{\circ}$ with $Z_{l 1}$ load), which results in a current THD of $28.2 \%$ and a PF of 0.66 .

Fig. 4 shows the instant of the SAPF connection in the PCC (1.0s), where $i_{g l}$ is the sum of the nonlinear load and DG currents.

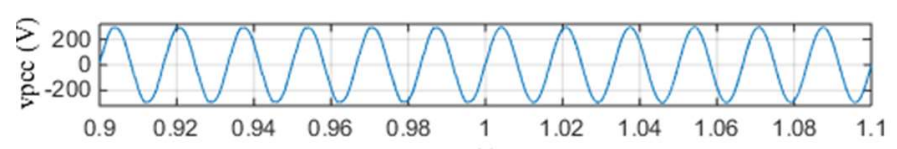

(a)

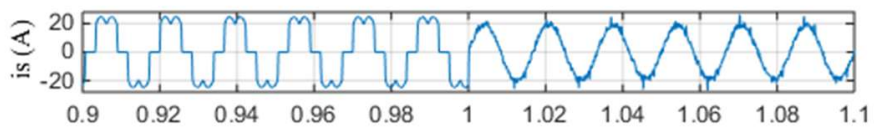

(b)

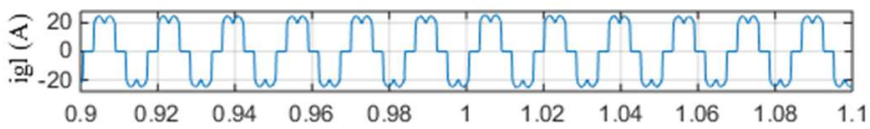

(c)

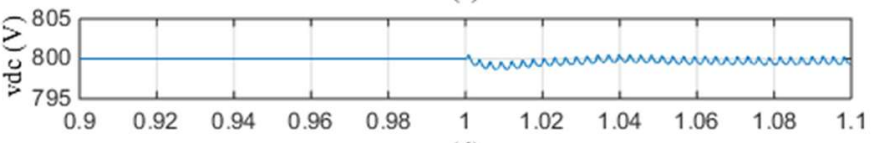

(d)

Fig. 4. PCC phase voltage, line currents and dc bus voltage on SAPF connection.

The SAPF performance provides a sinusoidal current with the same voltage phase, which results in a current THD of $3.2 \%$ and a PF of 0.989 . The control system dynamics ensures that the DC bus voltage is maintained with a ripple bellow of $1 \%$. In addition, there was improvement in the PCC voltage THD (decrease from $1.85 \%$ to $0.3 \%$ ) due to the considerable reduction of current THD.

Fig. 5 shows the real and imaginary instantaneous powers. Before the SAPF connection, the $p$ and $q$ profiles are considerably oscillating. After this (1.0s) the oscillating components are practically eliminated due to the harmonic compensation. The average instantaneous imaginary power component is also almost eliminated due to the reduction of the displacement factor between phase voltage and line current.

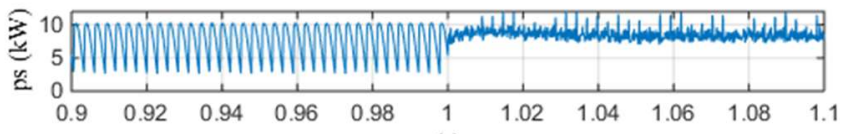

(a)

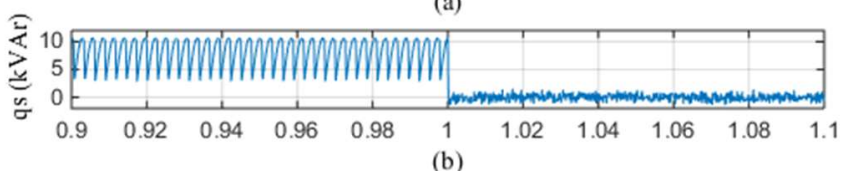

Fig. 5. Instantaneous power at the grid.

\section{B. DG Connection}

Fig. 6 shows the real and imaginary powers of the DG. The random wind behavior is directly reflected on the real power profile.

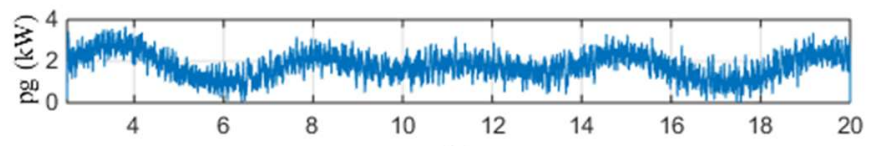

(a)

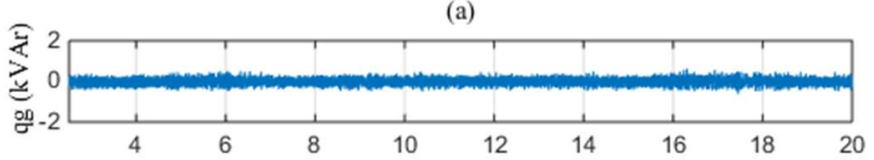

(b)

Fig. 6. Instantaneous power at the distributed wind generation. 
Fig. 7 shows the $i_{g l}$ current waveform, which results in a THD of $34 \%$. The SAPF current harmonic compensation provides a grid power current THD of $6 \%$. The DG-load set PF is 0.52 while the PCC PF is 0.982 . In this case, the DG connection causes a reduction on the $\bar{p}$ power grid component. However, there is an increase of oscillating power component $\tilde{p}$, resulting in high real power flows in the dc bus, requiring more effort and robustness of the controllers. In the implemented simulation, the intermittent $\tilde{p}$ comportment due to the DG-load set presence causes dc bus voltage oscillations less than $1 \%$.

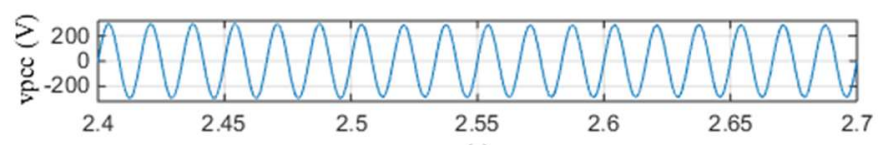

(a)

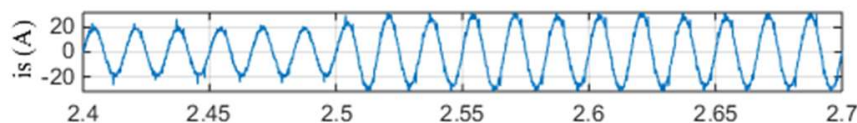

(b)

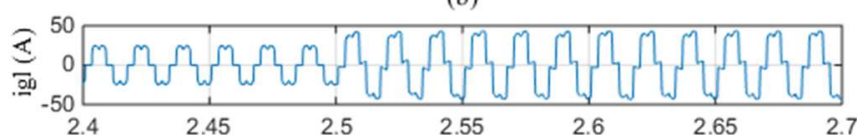

(c)

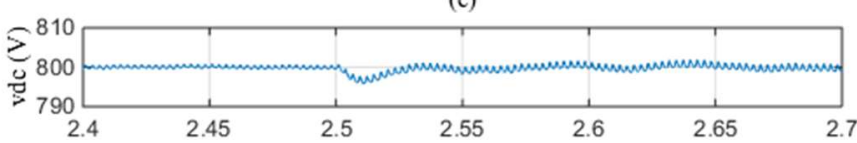

(d)

Fig. 7. PCC phase voltage, line currents and dc bus voltage on DG connection.

\section{Load Variations}

Fig. 8 shows the behavior of the system after change the impedance at the three-phase load for $Z_{l 2}$, step 4 . Although this load change results in the increase of the average and oscillating components of the instantaneous powers of the DG-load set, Fig. 9, the SAPF compensation guarantees that there is no significant non-active power flow through the grid, Fig. 10. This step results in a grid current THD of $8 \%$ and a PF of 0.978 , Fig. 11. The dc bus voltage ripple remains less than $1 \%$.

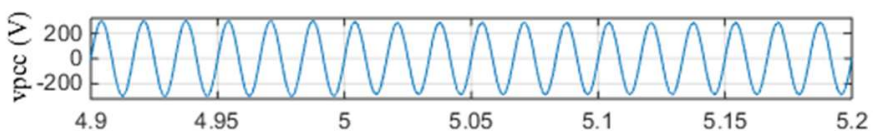

(a)

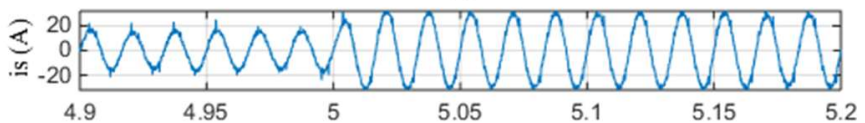

(b)

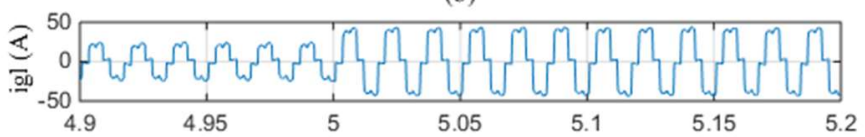

(c)

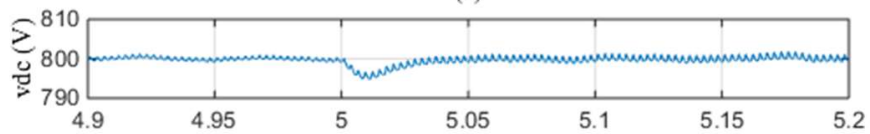

(d)

Fig. 8. PCC phase voltage, line currents and dc bus voltage on load change in step 4.
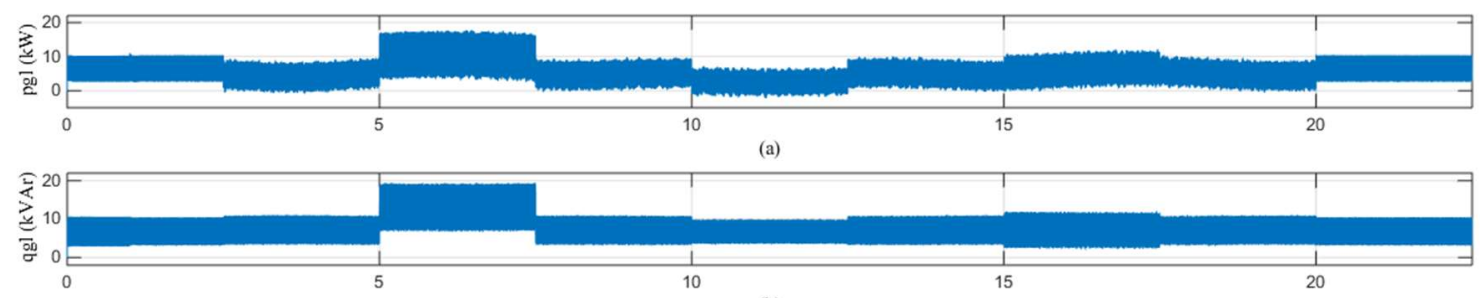

(b)

Fig. 9. DG-load set instantaneous power.

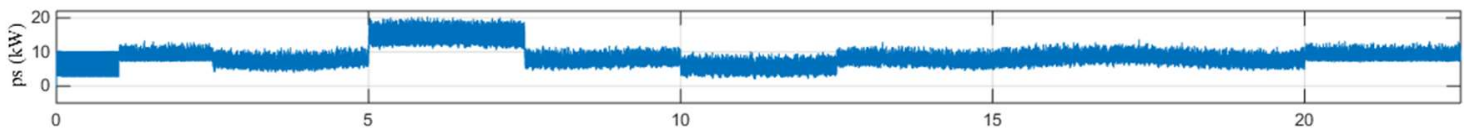

(a)

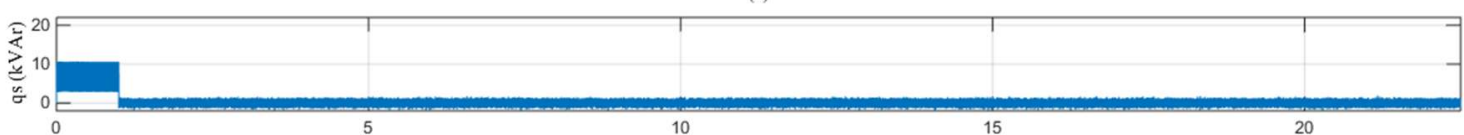

(b)

Fig. 10. Grid instantaneous power.
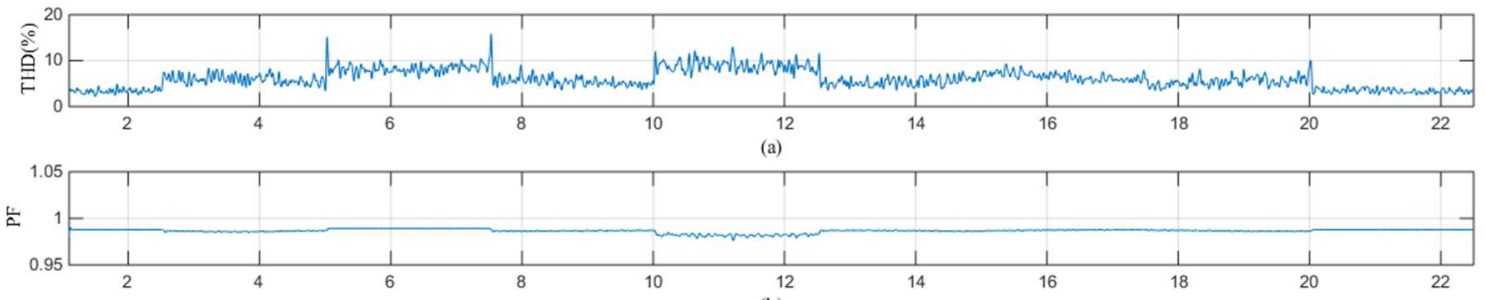

Fig. 11. (a) Grid current THD and (b) power factor of the grid. 
In the step 6 occurs a new load change related to the firing angle variation on thyristors of the three-phase rectifier, which is modified from $45^{\circ}$ to $55^{\circ}$, Fig. 12. The increase in the firing angle results in a decrease of the $\bar{p}$ power component, but the $\tilde{p}$ component and the imaginary power $q$ have small variations. In this operating condition occurs the worst SAPF compensation, resulting in a grid current THD of $10 \%$ and a PF of 0.972 .

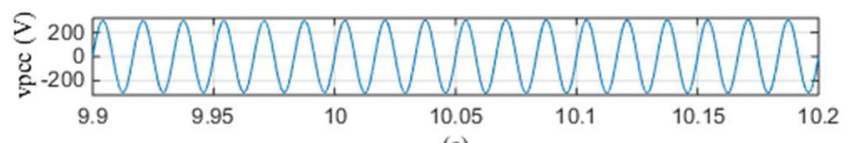

(a)

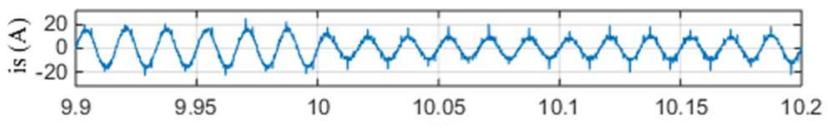

(b)

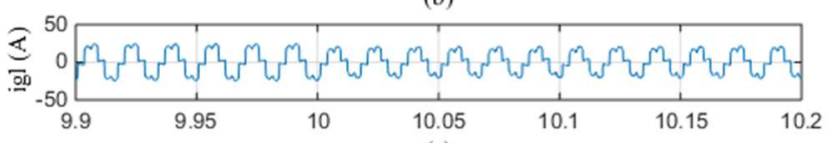

(c)

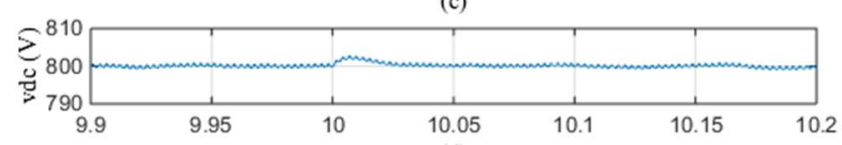

(d)

Fig. 12. PCC phase voltage, line currents and dc bus voltage on load change in step 6.

In step 8, a single-phase diode rectifier is connected between phases $a$ and $b$, feeding a $Z_{l 3}$ load, resulting in an unbalanced load. This condition resulting in an increase of the $\tilde{p}_{l}$ and $\tilde{q}_{l}$ load power component. The SAPF action on the system balances the line currents, Fig. 13, ensuring that the electrical grid almost not perceives the imbalance. This condition has a current THD of $6.8 \%$ and a PF of 0.988 .
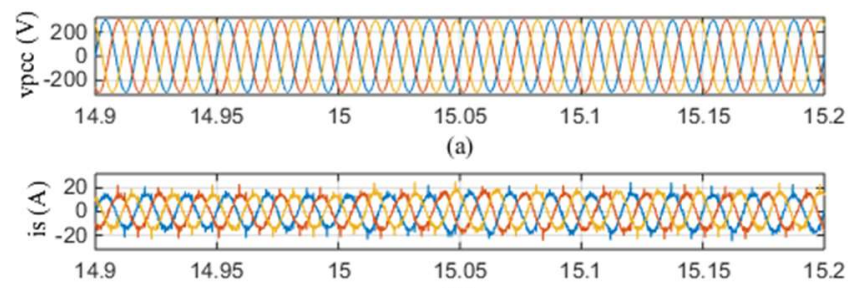

(b)

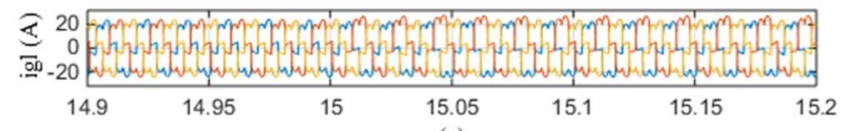

(c)

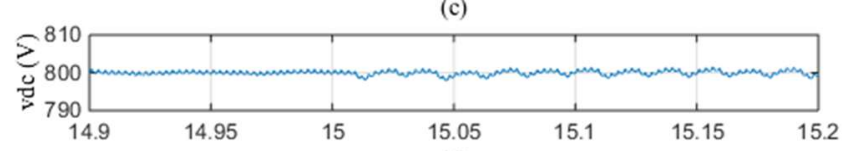

(d)

Fig. 13. PCC phase voltage, line currents and dc bus voltage on load change in step 8.

\section{CONCLUSION}

This paper used a shunt active power filter for power quality improvement of the low voltage power distribution system with DG unit. From the simulation results, was observed that the transient and steady state response, comparing the waveforms, current THD and power factor of the system, ensure satisfactory responses. The efficiency of the filter remained even in the face of variations in the load and operation of the DG with wave characteristic typical of a wind system. The high harmonics of the nonlinear loads and DG unit removed by the SAPF, prove that the linear quadratic controller with integral action regulator (LQRI) designed operates properly.

\section{REFERENCES}

[1] R. L. A. Ribeiro, T. O. A. Rocha, R. M. de Sousa, E. C. Santos Jr., and A. M. N. Lima, "A robust dc-link voltage control strategy to enhance the performance of shunt active power filters without harmonic detection schemes", IEEE Transactions on Industrial Electronics, vol. 62, no. 2, pp. 803-813, Feb 2015.

[2] G. Ahrabian, F. Shahnia, and M. T. Haque, "Hybrid Filter Applications for Power Quality Improvement of Power Distribution Networks Utilizing Renewable Energies," IEEE ISIE 2006. Montreal, Quebec, Canada. pp. 1161-1165, July 9-12, 2006.

[3] J. Dolezal, P. Santarius, J. Tlusty, V. Valouch, and F. Vybiralik, "The effect of dispersed generation on power quality in distribution system", CIGRE/IEEE Int. Symposium on Quality and Security of Electric Power Delivery Systems, pp. 204-207, Oct. 2003.

[4] P. Verdelho and G. D. Marques, "An active power filter and unbalanced current compensator," IEEE Transactions on Industrial Electronics, v. 44, n. 3, p. 321-328, June 1997.

[5] H. Akagi, "Trends in active power line conditioners," IEEE Trans. Power Electron., vol. 9, no. 3, pp. 263-268, May 1994.

[6] F. Z. Peng, "Application Issues of Active Power Filters" Proc. 7th Int Conf. Harmonics and Quality of Power, Las Vegas, NV, pp. 21-30, 2009.

[7] B. Singh and V. Verma, "Selective compensation of power-quality problems through active power filter by current decomposition," IEEE Trans. Power Del., vol. 23, no. 2, pp. 782-799, Apr. 2008.

[8] B. Singh, K. Al-Haddad, and A. Chandra, "A review of active filters for power quality improvements," IEEE Trans. Ind. Electron., vol. 46, no. 5, pp. 960-971, Oct. 1999.

[9] F. A. S. Neves, H. E. P. de Souza, M. C. Cavalcanti, F. Bradaschia, and E. J. Bueno, "Digital filters for fast harmonic sequence component separation of unbalanced and distorted three-phase signals," IEEE Trans. Ind. Electron., vol. 59, no. 10, pp. 3847-3859, Oct. 2012.

[10] S. Bhattacharya, T. M. Frank, D. M. Divan, and B. Banerjee, "Active filter system implementation,” IEEE Ind. Appl. Mag., vol. 4, no. 5, pp. 47-63, sep./oct. 1998.

[11] F. Z. Peng, G. W. Ott, Jr., and D. J. Adams, "Harmonic and reactive power compensation based on the generalized instantaneous reactive power theory for three phase four wire system," IEEE Trans. Power Electron., vol. 13, no. 6, pp. 1174-1181, Nov. 1998.

[12] R. L. A. Ribeiro, C. C. de Azevedo, and R. M. de Sousa, "A robust adaptive control strategy of active power filters for power-factor correction, harmonic compensation, and balancing of nonlinear loads," IEEE Trans. Power Electron., vol. 27, no. 2, pp. 718-730, Feb. 2012.

[13] T. E. Nunez-Zuniga, and J. A. Pomilio, "Shunt active power filter synthesizing resistive load," IEEE Trans. Power Electron., vol. 17, no. 2, pp. 273-278, Mar. 2002.

[14] Z. Chen, Y. Luo, and M. Chen, "Control and performance of a cascaded shunt active power filter for aircraft electric power system," IEEE Trans. Ind. Electron., vol. 59, no. 9, pp. 3614-3623, Sep. 2012.

[15] Q. Trinh and H. Lee, "An advanced current control strategy for threephase shunt active power filter," IEEE Trans. Ind. Electron., vol. 60, no. 12, pp. 5400-5410, Sep. 2013.

[16] H. Akagi, E. H. Watanabe, M. Arede, Instantaneous Power Theory and Applications to Power Conditioning, IEEE Press, John Wiley \& Sons, Hoboken, New Jersey, 2007.

[17] B. Kedjar and K. Al-Haddad, "LQR with integral action to enhance dynamic performance of three-phase three-wire shunt active filter," in Proc. IEEE-PESC, Orlando, FL, pp. 1138-1144, Jun. 2007.

[18] M. A. Johnson and M. J. Grimble, "Recent trends in linear optimal quadratic multivariable control systems design," Proc. Inst. Elect. Eng.Control Theory Appl., vol. 134, no. 1, pp. 53-71, Jan. 1987. 